\title{
Model Construction and Performance Degradation Characteristics of a Deflector Jet Pressure Servo Valve under the Condition of Oil Contamination
}

\author{
Yuanbo Chu ${ }^{1},{ }^{1}$ Zhaohui Yuan, ${ }^{2}$ Xuegong He, ${ }^{3}$ and Zhichao Dong ${ }^{3}$ \\ ${ }^{1}$ School of Photoelectric Engineering, Xi'an Technological University, Xi'an 710021, China \\ ${ }^{2}$ School of Automation, Northwestern Polytechnical University, Xi'an 710129, China \\ ${ }^{3}$ AVIC Aircraft Co., Ltd. Xi'an Brake Branch, Xi'an 710056, China \\ Correspondence should be addressed to Yuanbo Chu; chuyuanbo528@163.com
}

Received 21 March 2020; Revised 23 January 2021; Accepted 6 February 2021; Published 27 February 2021

Academic Editor: Jose Carlos Páscoa

Copyright (C) 2021 Yuanbo Chu et al. This is an open access article distributed under the Creative Commons Attribution License, which permits unrestricted use, distribution, and reproduction in any medium, provided the original work is properly cited.

\begin{abstract}
The deflector jet pressure servo valve is a kind of high-precision hydraulic component that can be widely used in the antiskid braking system of an aircraft. In actual service, it will be faced with extreme working conditions of gradual oil contamination, which will cause performance degradation and function maladjustment of the whole valve. To this end, the paper proposes a performance degradation characteristic analysis method. In which, firstly, the structural characteristics and working principle of the deflector jet pressure valve are analyzed; then, the entire dynamics model of the pressure valve is built using the braking cavity as the load blind cavity. Secondly, the two main failure modes induced by oil contamination such as erosion wear of pilot stage and stuck of slide valve stage's valve core are determined based on the engineering experience, aimed at which the failure mechanism is analyzed; then, the sensitivity simulation model of the servo valve's output pressure with respect to key degradation parameters is established and the sensitivity analysis is performed. Finally, combining the theoretical analysis with multiphysics simulation correction methods, the performance degradation model of the typical failure modes are established, and then, the performance degradation characteristics under dynamic contamination conditions are analyzed, which is combined with the failure threshold determined by the dynamics simulation to finish the service life prediction of the deflector jet servo valve.
\end{abstract}

\section{Introduction}

An electrohydraulic servo valve is the core hydraulic component of electrohydraulic control, after receiving the input electric control signal, which outputs corresponding modulated flow or pressure. Among them, the pressure servo valve with pressure as output is essentially a relief valve, which has the advantages of fast response, high sensitivity, large output power, and controllable output pressure [1]. The pressure valve was first used in the antiskid braking system of an aircraft around 1950. After nearly 70 years' development, a two-stage pressure valve can be applied to the antiskid braking system mainly including the nozzle flapper servo valve, jet pipe servo valve, direct drive servo valve, and deflector jet servo valve. The working environment of a highly reliable antiskid braking system of the aircraft determines the basis for evaluating the performance of the pressure valve involving the pilot stage's driving force, static and dynamic performances, and anticontamination performance [2].

The design and process technology of the nozzle flapper pressure valve are mature. The flapper of the pilot stage's moving part has a small inertia, fast response speed, and high control sensitivity. However, the size between nozzle and flapper is just $0.03 \mathrm{~mm}-0.05 \mathrm{~mm}$, which has the drawbacks of easy block, poor anticontamination ability, and can only work under NAS6 or NAS7 oil for a long time. In the pilot stage of the jet pipe pressure valve, the $0.2 \mathrm{~mm}-0.4 \mathrm{~mm}$ clearance between the nozzle and receiver determines its relatively high anticontamination ability, which can also work normally at the oil level of GJB420B 9, but the jet pipe amplifier 
has shortcomings including complicated structure, more welding parts, stress concentration, poor stiffness of impulse pipe, and insufficient pressure stability. The direct drive pressure valve formed by replacing the hydraulic pilot stage with an electronic drive has the advantages of small size, light weight, strong anticontamination ability, and good performance. However, the pilot drive capacity of the electric feedback form is low, and the volume of servo valve for required driving force is too large to meet the requirements. To overcome the above deficiencies, the deflector jet pressure servo valve is proposed which integrates the main advantages of the three pressure valves [3].

The deflector jet pressure servo valve uses the principle of the jet pipe servo valve [4], and a deflector plate is added between the jet outlet and the receiver, by which the deflection of jet pipe is replaced with the deflection of deflection plate controlled by the torque motor to realize the pilot stage jet control. Because the gap among the nozzle of the jet sheet, the deflector plate, and the jet plate are large, it has the advantages of not easy to block, strong driving ability, strong anticontamination ability, and small inertia of moving parts. In order to meet the stable pressure output, the clearance between the spool valve and valve sleeve is only $2 \mu \mathrm{m}-4 \mu \mathrm{m}$. Oil contamination will not only cause erosion wear on the working surface of pilot stage but also induce the valve core's stuck of the spool stage, which will bring about performance degradation of the deflector jet pressure valve and even cause a major failure of the braking system. Therefore, the model construction, performance degradation characteristic analysis, and service life prediction of the deflector jet pressure valve under oil contamination are a major issue that needs to be solved urgently.

At present, the public literature related to the deflector jet pressure valve is less. Only AVIC has given a new type of deflector jet pressure valve; the mechanism of torque motor, deflector jet amplifier, and slide valve has been studied, and the whole valve model has been established, which has certain theoretical support for the development of the deflector jet pressure valve [3]. However, there are many researches about the pilot stage which can be divided into three aspects $[5,6]:(1)$ the performance researches about traditional deflector jet servo valve. The researches mainly take pressure characteristics and flow characteristics as starting point, then establish corresponding mathematical models to analyze and infer the key factors affecting the performance of servo valve $[7,8]$. (2) Structural improvement of deflector jet servo valves: the improvement works mainly focuses on the optimization of key structural parameters of the pilot stage [9, 10]. (3) Process technology improvement of the deflector jet servo valve: carrying out the process improvement studies to improve the process quality of the pilot stage [11]. At the same time, there are also researches involving the erosion wear and the reliability of the servo valve. For the erosion of the jet pipe servo valve's pilot stage, the trajectory of the oil and particles in the multiphase flow was analyzed by Yin et al.; then, the influence law of parameters such as the velocity and impact angle of particles to the erosion wear was carried out [12]. Based on the Fluent software, Chu et al. established a visual simulation model of nozzle to receiver in the pilot stage, then carried out simulation of erosion rate and calculation of the servo valve's theoretical life [13, 14]. Based on the GSPN theory, collected basic failure modes, and failure rate data of the jet pipe servo valve, Chu et al. propose a novel modeling and simulating method for the system's dynamic behavior [15]. The oil flow and particle's moving trajectory of the deflector jet servo valve's pilot stage was analyzed by Ji et al.; then, the maximum speed of particles with different diameters and its influence on the erosion for the pilot stage were calculated [16]. The rest of research is mainly based on the comparison between pilot stage clearance size and particle size and then qualitatively gives other types of servo valves' advantages and disadvantages [17], or qualitatively analysis through experiments to show the oil quality control should be strengthened [18]. Based on the above, the main deficiencies of the current performance degradation characteristics of the deflector jet pressure valve under oil contamination conditions are as follows: (1) most analyses about the performance of the pilot stage are only the qualitative analysis, (2) without considering the performance degradation of oil contamination to the special clearance structure of the slide valve stage, (3) the influence of oil pollution level is not considered, and (4) the quantitative analysis of the performance degradation and service life of the entire valve under oil contamination are not performed.

To solve these issues, this paper is focused on the performance degradation characteristics of a DJPSV induced by oil contamination. Firstly, the entire valve dynamics model is built using the braking cavity as the load blind cavity. Secondly, the two main failure modes induced by oil contamination such as erosion of pilot stage and stuck of valve core are determined based on the engineering experience, aimed at which the failure mechanism is analyzed; then, the sensitivity simulation model of the servo valve's output pressure with respect to key degradation parameters are established and the sensitivity analysis is performed. Finally, combining the theoretical analysis with multiphysics simulation correction methods, the performance degradation model of the typical failure modes is established, and then, the performance degradation characteristics under dynamic pollution conditions are analyzed, which is combined with the failure threshold determined by the dynamics simulation to finish the service life prediction of the deflector jet servo valve.

\section{Structural Feature and Working Principle of the DJPSV}

The deflector jet pressure valve is composed of a torque motor, armature-deflection plate assembly, jet amplifier, and slide valve assembly. The structure of deflector jet pressure valve is shown in Figure 1, where $R, P, J$, and $S$ represent the oil return port, slide valve pressure inlet, pilot stage pressure inlet, and braking port of the servo valve, respectively; $P$ and $J$ provide $21 \mathrm{MPa}$ oil pressure for the servo valve, and when the braking port $J$ is connected with the braking system of the aircraft, the braking cavity is a special blind cavity structure.

When the control signal is input to the coil of the servo valve, a control torque is generated to the armature assembly, 


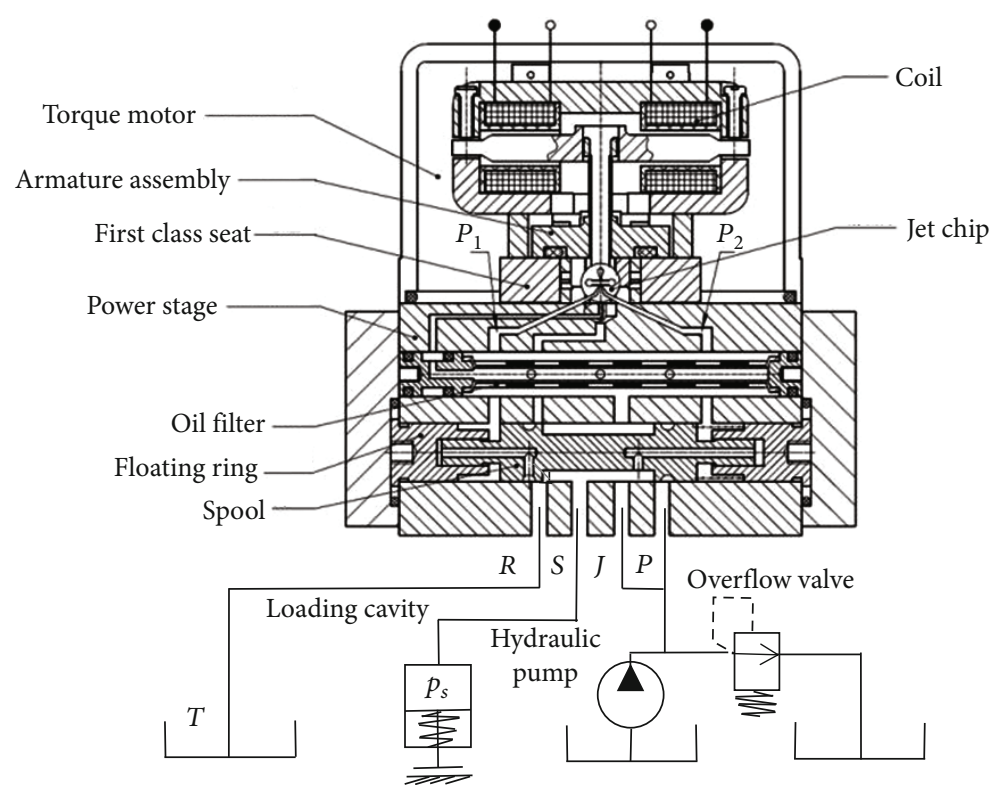

Figure 1: The structure of the deflector jet pressure servo valve.

which makes the armature assembly deflect clockwise, the deflector plate deviate to the left, and a control pressure difference is generated on the annular surface at both ends of the valve core, which makes the valve core move to the right, the oil return control edge is gradually closed, the oil inlet control edge is gradually opened, and the braking pressure is increased. When the control force acting on the valve core is balanced with the feedback force, the valve core is stable at a certain position (the oil inlet, the brake port and the oil return port are not mutually connected), and the servo valve outputs a braking pressure proportional to the input current to realize the pressure control with positive gain.

\section{Mathematical Model of the DJPSV}

3.1. Mathematical Model of the Torque Motor. The function of a torque motor in the servo valve is to convert electrical signal into mechanical motion, after receiving input current signal $i_{c}$ output the final driving torque $T_{m}$ :

$$
T_{m}=K_{t} i_{c}+K_{m} \theta
$$

where $K_{t}=(2 a / L) N_{c} \phi_{g}$ is the middle position electromagnetic torque coefficient of torque motor. $K_{\mathrm{m}}=4(a / l)^{2} \phi_{g}^{2} R_{g}$ is the electromagnetic spring stiffness of the torque motor. $a$ is the radius from the armature shaft to the center of the guide magnet. $L$ is the length of the armature. $N_{c}$ is the coil turns. $\varphi_{g}$ is the fixed flux. $R_{g}$ is the reluctance. $\theta$ is the deflector angle of the armature.

The stable process of the armature assembly is the balance process of various moments acting on it; the motion equation of the armature assembly is as follows:

$$
T_{m}=\left(J_{a} s^{2}+B_{a} s+K_{a}\right) \theta
$$

where $J_{a}$ is the moment inertia of the armature assembly. $B_{a}$ is the viscous damping coefficient of the armature assembly. $K_{a}$ is the spring pipe stiffness.

The deflector plate deflects under the action of the torque motor, the deflector angle is $\theta$, and the deflector displacement is $x_{f}$; their relation is expressed as follows:

$$
x_{f}=r \theta
$$

where $r$ is the distance from the end of deflector plate to its rotating center.

3.2. Mathematical Model of the Jet Amplifier. The deflector jet amplifier is a nonthrottling hydraulic amplifier. The deflector deflects a relative position of the receiver, which results in a pressure difference between the two receiving holes, so as to realize the conversion and amplification of the control slide valve. The relation between the pressure difference $\Delta P$ of the two cavities and the offset distance $x_{f}$ of the deflector is deduced as

$$
\Delta P=k_{p} x_{f}
$$

\subsection{Mathematical Model of the Slide Valve}

3.3.1. The Force Balance Equation of Main Valve Core. The valve core is driven by combined action of the pressure difference of control chamber and the pressure difference of the feedback chamber and the return spring. When the valve core moves in the valve sleeve, the force it receives also includes inertia force, damping force, and friction force. Therefore, the dynamic equation of the deflector jet pressure valve's valve core can be expressed as

$$
\Delta P A_{v}-\left(P_{s}-P_{r}\right) A_{f}=m_{v} \ddot{x}_{v}+B_{v} \dot{x}_{v}+K_{h} x_{v}+F_{f},
$$




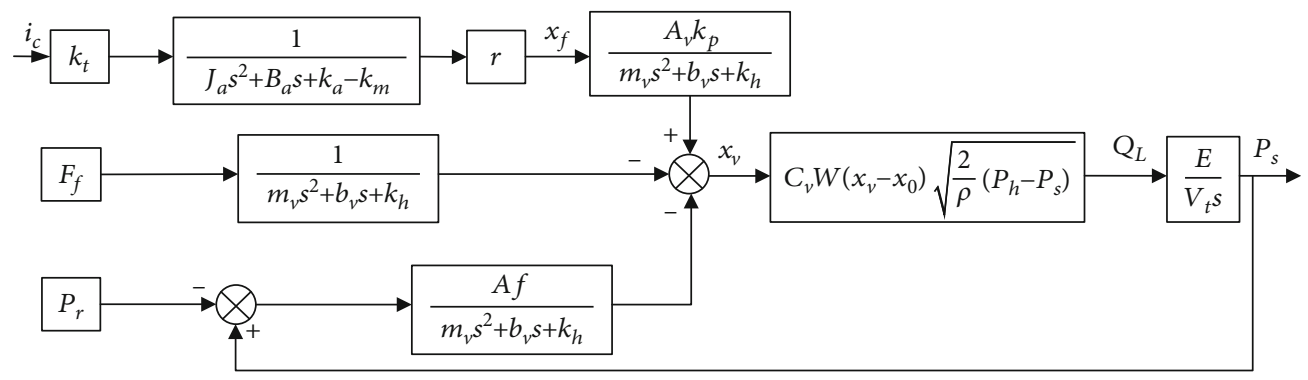

FIGURE 2: The dynamic characteristic block diagram of the deflector jet pressure valve.

where $x_{v}$ is the displacement of the valve core. $P_{s}$ is the braking pressure. $P_{r}$ is the return prerssure. $m_{v}$ is the quality of valve core. $B_{v}$ is the viscous damping of valve core and load. $K_{h}$ is the stiffness of the return spring. $F_{f}$ is the friction between the spool and sleeve mainly induced by hydraulic stagnation and contamination stagnation, which is calculated as

$$
F_{f}=F_{f 1}+F_{f 2}
$$

where $F_{f 1}$ is the friction induced by contamination stagnation and $F_{f 2}$ is the friction induced by hydraulic stagnation.

The friction induced by hydraulic stagnation $F_{f 2}$ is calculated as

$$
F_{f 2}=2 k_{o} k_{j y} l_{v o} d_{v o} \Delta P_{v o}
$$

where $k_{o}$ is the hydraulic stagnation coefficient. $k_{j y}$ is the influence coefficient of three equalizing grooves on the hydraulic stagnation force. $l_{v o}$ is the shoulder length of valve core. $d_{v o}$ is the diameter of the valve core at shoulder. $\Delta P_{v o}$ is the pressure difference between both sides of the shoulder.

3.3.2. Flow Equation of the Slide Valve. When the deflector plate deflects in the positive direction, the pressure difference between the control chambers causes the valve core to move in the positive direction, and the input high-pressure oil enters the braking chamber to increase the braking pressure. Simultaneously, the braking chamber is connected with the feedback chamber on one side of the valve core, and the return oil is connected with the feedback chamber on the other side to generate the pressure difference of the feedback chamber. The flow from oil supply inlet to braking chamber is

$$
Q_{L}=C_{v} W\left(x_{v}-x_{0}\right) \sqrt{\frac{2}{\rho}\left(P_{h}-P_{s}\right)},
$$

where $C_{v}$ is the flow coefficient. $W$ is the area gradient of valve core opening. $x_{v}$ is the displacement of spool core. $x_{0}$ is the overlap between spool core and spool sleeve.. $P_{h}$ is the supply oil pressure. $P_{s}$ is the braking pressure.

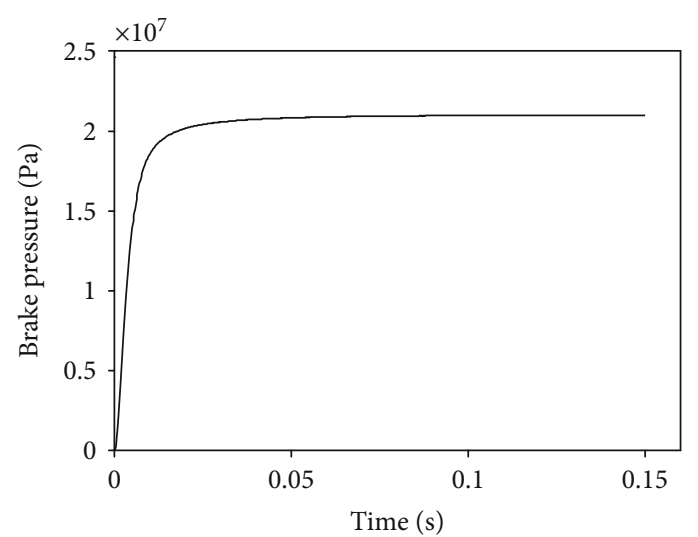

FIGURE 3: The pressure response of DJPSV.

The linearized equation of Equation (8) is showed as

$$
Q_{L}=k_{q} x_{v}-k_{c}\left(P_{h}-P_{s}\right),
$$

where $k_{q}$ is the flow amplification coefficient. $k_{c}$ is the flow pressure amplification coefficient.

Furthermore, the relation between the load flow $Q_{L}$ and the braking chamber pressure $P_{s}$ is shown as

$$
Q_{L}=\frac{V_{t}}{E} s P_{s}
$$

where $E$ is the hydraulic oil bulk modulus.

3.4. Mathematical Model of the Entire Valve. Based on Equations (1)-(10), the dynamic characteristic block diagram of the deflector jet pressure valve can be obtained as Figure 2 .

Building a MATLAB/SIMULINK simulation program, the pressure response of the deflector jet servo valve when the step current is input is shown in Figure 3. It can be seen under the initial structural parameters that the system pressure quickly stabilizes at $21 \mathrm{MPa}$ after receiving the $60 \mathrm{~mA}$ input signal. However, the output pressure will gradually deteriorate because of the extension of service time and the increase of the contamination oil level. 


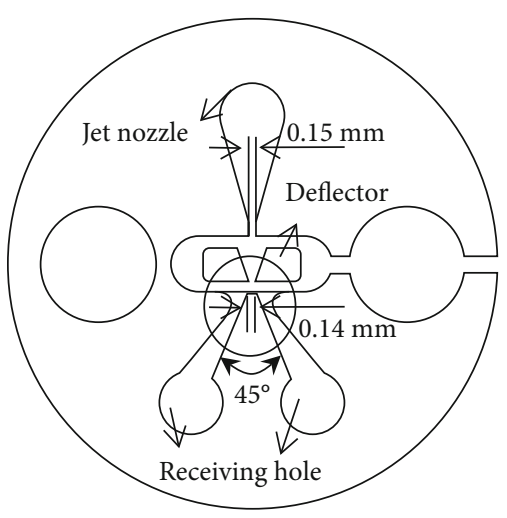

(a) The profile of pilot stage's core structure

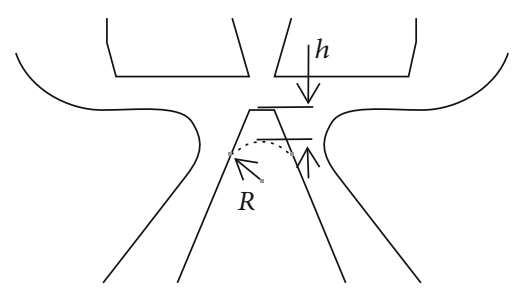

(b) Comparison before and after erosion wear

FIgURE 4: Diagram of pilot stage's erosion wear.

\section{Oil Contamination Sensitivity of the DJPSV}

4.1. Dominant Mode of Gradual Failure Induced by Oil Contamination. By performing FMEA on the deflector jet pressure valve, it can be found that oil contamination is the main and the highest probability cause of servo valve's failure. Failure modes caused by oil contamination include sudden failures and gradual failures. The so-called gradual failures mean with the extension of service life, a certain performance index of the servo valve, cannot be maintained within the specified normal range. The gradual failure mode of the deflector jet pressure valve due to oil contamination mainly includes erosion wear of pilot stage and spool movement failure of slide valve stage.

(1) The erosion wear of pilot stage. Erosion wear is defined as the process of material loss when the solid surface contacts with the fluid containing particles and moves relatively, in which the particle diameter is usually less than $1 \mathrm{~mm}$ and the particle speed is not more than $550 \mathrm{~m} / \mathrm{s}$. As shown in Figure 4, a certain number of particles are ejected from the jet nozzle along with the oil. After encountering the deflector, they impact on the inner wall of the wedge and the receiving holes on both sides at a certain speed and angle and produce erosion wear, which leads to the performance degradation of the jet amplifier and affects the performance of the whole pressure valve

(2) Spool movement failure of slide valve stage. Under the two conditions of valve core's frequent action and long-time static, the movement failure of valve core induced by oil contamination comes from two different failure mechanisms. For the long-time static valve core, the clamping force mainly comes from the friction caused by the filter cake during the static time, which has certain regularity. In the deflector jet pressure valve, after the valve core is stationary for a certain time, "sensitive particles," will enter the clearance between the valve core valve sleeve, some of the contaminated particles will flow out of the

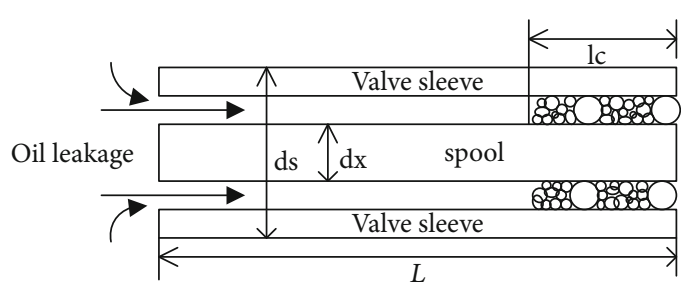

FIgURE 5: The diagram of filter cake formation induced by oil contamination

clearance along with the leakage fluid, some of them will be trapped in the clearance, they will intercept other contaminated particles, after which the filter cake will be formed in the clearance shown in Figure 5, which will affect the response of slide valve. When the driving force is not big enough to push the valve core, the slide valve fails to move.

4.2. Sensitivity Analysis about the Deterioration Parameters. Based on the mathematical model and assuming $x_{1}=P_{s}, x_{2}$ $=\dot{P}_{s}$, and $x_{3}=\ddot{P}_{s}$, the state space model of DJPSV can be obtained as Equation (11). From which, the factors affecting system performance caused by oil contamination include pressure gain $k_{p}$ of pilot stage and stuck friction $F_{f 1}$ of the valve core, the erosion can cause the changing of $k_{p}$, and the stuck of the valve core will raise the value of $F_{f 1}$. Therefore, it is necessary to carry out the sensitivity analysis of DJPSV to $k_{p}$ and $F_{f 1}$, that is, to analyze the sensitivity of key parameters induced by oil contamination.

$$
\left\{\begin{array}{l}
y=x_{1}, \\
\dot{x}_{1}=x_{2}, \\
\dot{x}_{2}=x_{3}, \\
\dot{x}_{3}=-k_{1} x_{1}-k_{2} x_{2}-k_{3} x_{3}+b u-d F_{f}+c P_{r}+g P_{h},
\end{array}\right.
$$


where $k_{1}=\left(-k_{h} k_{c} E+E A_{f} K_{q}\right) / m_{v} V_{t}$,

$$
\begin{aligned}
k_{2} & =\frac{k_{h} V_{t}-B_{v} k_{c} E}{m_{v} V_{t}}, \\
k_{3} & =\frac{B_{v} V_{t}-m_{v} k_{c} E}{m_{v} V_{t}}, \\
b & =\frac{k_{p} k_{q} k_{t} r A_{v} E}{\left(k_{a}-k_{m}\right) m_{v} V_{t}}, \\
d & =\frac{k_{q} E}{m_{v} V_{t}}, \\
c & =\frac{A_{f} k_{q} E}{m_{v} V_{t}}, \\
g & =\frac{-k_{c} k_{h} E}{m_{v} V_{t}} .
\end{aligned}
$$

The sensitivity analysis of key parameters induced by oil contamination is carried out using the first-order trajectory sensitivity model. Trajectory sensitivity is to study the change of state vector caused by the change of parameters according to the state equation. The state equation of the DJPSV can be expressed as

$$
\dot{x}=f(x, u, \alpha, t) \text {, }
$$

where $x$ is $N$-dimensional state vector, $u$ is $R$-dimensional input independent of $\alpha$, and $t$ is time.

The solution of Equation (13) is

$$
x_{n}(t)=\varphi\left(t, \alpha_{n}\right) .
$$

The sensitivity function of vector $x$ to parameter $\alpha$ and its initial condition are defined as

$$
\begin{aligned}
& \lambda^{i}=\frac{\partial x}{\partial \alpha_{i}}, i=1,2, \cdots p, \\
& \lambda_{0}^{i}=\frac{\partial x_{0}}{\partial \alpha_{i}}, i=1,2, \cdots, p .
\end{aligned}
$$

In this work, $u$ and $\alpha$ are independent, taking the derivative of Equation (13) on both sides of $\alpha$ as

$$
\dot{\lambda}^{i}=\left(\frac{\partial f}{\partial x}\right)_{n} \lambda^{i}+\left(\frac{\partial f}{\partial \alpha_{i}}\right)_{n}, i=1,2, \cdots, p
$$

Select related vector of the DJPSV as

$$
\left\{\begin{array}{l}
x=\left(x_{1}, x_{2}, x_{3}\right), \\
u=(u), \\
\alpha=\left(\alpha_{1}, \alpha_{2}, \cdots, \alpha_{17}\right),
\end{array}\right.
$$

where the state vector parameter of the DJPSV is $x_{1}=P_{s}, x_{2}$ $=\dot{P}_{s}$, and $x_{3}=\ddot{P}_{s}$; the input vector parameter is $u=i_{c}$; the parameter vector parameter is $\alpha_{1}=K_{h}, \alpha_{2}=k_{c}, \alpha_{3}=E, \alpha_{4}=$ $m_{v}, \alpha_{5}=V_{t}, \alpha_{6}=A_{f}, \alpha_{7}=k_{p}, \alpha_{8}=k_{q}, \alpha_{9}=B_{v}, \alpha_{10}=k_{t}, \alpha_{11}=$ $A_{v}, \alpha_{12}=r, \alpha_{13}=k_{a}, \alpha_{14}=k_{m}, \alpha_{15}=F_{f}, \alpha_{16}=P_{r}$, and $\alpha_{17}=$ $P_{h}$.

Then, the state space model of the DJPSV can be expanded into

$$
\left\{\begin{array}{l}
y=x_{1}, \\
\dot{x}_{1}=x_{2}, \\
\dot{x}_{2}=x_{3}, \\
\dot{x}_{3}=-\frac{-\alpha_{1} \alpha_{2} \alpha_{3}+\alpha_{3} \alpha_{6} \alpha_{8}}{\alpha_{4} \alpha_{5}} x_{1}-\frac{\alpha_{1} \alpha_{5}-\alpha_{2} \alpha_{3} \alpha_{9}}{\alpha_{4} \alpha_{5}} x_{2}-\frac{\alpha_{5} \alpha_{9}-\alpha_{2} \alpha_{3} \alpha_{4}}{\alpha_{4} \alpha_{5}} x_{3}+\frac{\alpha_{3} \alpha_{7} \alpha_{8} \alpha_{10} \alpha_{11} \alpha_{12}}{\left(\alpha_{13}-\alpha_{14}\right) \alpha_{4} \alpha_{5}} u-\frac{\alpha_{3} \alpha_{8} \alpha_{15}}{\alpha_{4} \alpha_{5}}+\frac{\alpha_{3} \alpha_{6} \alpha_{8} \alpha_{16}}{\alpha_{4} \alpha_{5}}+\frac{-\alpha_{1} \alpha_{2} \alpha_{3} \alpha_{17}}{\alpha_{4} \alpha_{5}} .
\end{array}\right.
$$

The partial derivative of state equation function to the state vector $x$ is conducted; then, the coefficient term of sensitivity function can be obtained as

$$
\left\{\begin{array}{l}
\frac{\partial f}{\partial x_{1}}=\left(0,0,-\frac{-\alpha_{1} \alpha_{2} \alpha_{3}+\alpha_{3} \alpha_{6} \alpha_{8}}{\alpha_{4} \alpha_{5}}\right)^{T} \\
\frac{\partial f}{\partial x_{2}}=\left(1,0,-\frac{\alpha_{1} \alpha_{5}-\alpha_{2} \alpha_{3} \alpha_{9}}{\alpha_{4} \alpha_{5}}\right)^{T} \\
\frac{\partial f}{\partial x_{3}}=\left(0,1,-\frac{\alpha_{5} \alpha_{9}-\alpha_{2} \alpha_{3} \alpha_{4}}{\alpha_{4} \alpha_{5}}\right)^{T}
\end{array}\right.
$$

The partial derivative of state equation function to the state vector $\alpha$ is conducted; then, the free term of sensitivity function can be obtained as

$$
\begin{aligned}
\frac{\partial f}{\partial \alpha_{7}} & =\left(0,0, \frac{\alpha_{3} \alpha_{8} \alpha_{10} \alpha_{11} \alpha_{12}}{\left(\alpha_{13}-\alpha_{14}\right) \alpha_{4} \alpha_{5}} u\right)^{T}, \\
\frac{\partial f}{\partial \alpha_{15}} & =\left(0,0,-\frac{\alpha_{3} \alpha_{8}}{\alpha_{4} \alpha_{5}}\right)^{T} .
\end{aligned}
$$

The initial value of state vector $x$ is $x_{0}=0$; then, the initial value of sensitivity function is 


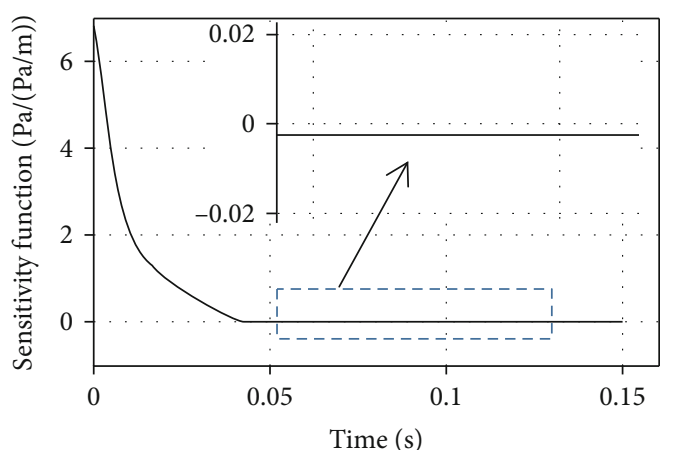

(a) Sensitivity function $\lambda_{1}^{7}$

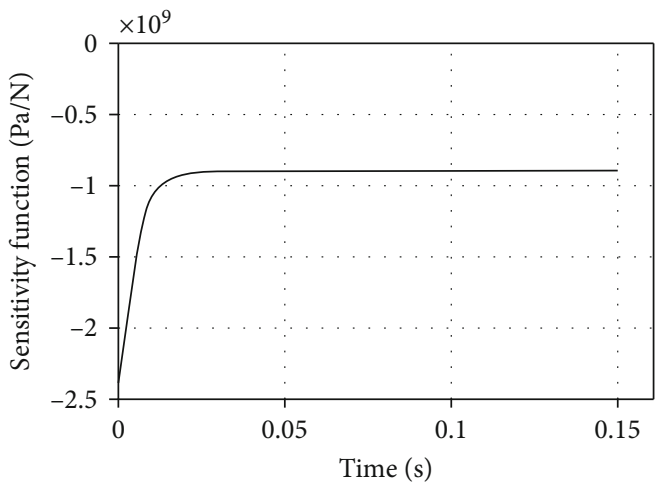

(b) Sensitivity function $\lambda_{1}^{15}$

Figure 6: Curves of sensitivity function.

$$
\lambda_{0}^{i}=0, i=1,2, \cdots, 11 .
$$

Based on the simulation model, the differential equation is solved in the command interface of MATLAB using the fourth-order/fifth-order Runge-Kutta algorithm; then, the sensitivity function $\lambda_{1}^{i}(i=7,15)$ of step response $x_{1}$ to parameter $\alpha_{i}(i=7,15)$ are shown in Figure 6.

According to the curves of sensitivity function shown in Figure 6, the sensitivity of the system decreases rapidly in the dynamic response process and gradually stabilizes to a nonzero value in the steady state process, that is, the change of $k_{p}$ and $F_{f 1}$ will affect system performance in the whole response process and the friction induced by hydraulic stagnation $F_{f 2}$ is simplified as constant. Therefore, it is necessary to analyze the failure modes' law induced by oil contamination and will finally bring out performance degradation of the deflector jet pressure servo valve.

\section{Performance Degradation Characteristics and Service Life Prediction of the DJPSV}

\subsection{The Erosion Wear of Pilot Stage}

\subsubsection{Mathematical Model of the Degradation Process}

(1) Basic Fluid Flow. Neglecting the heat conduction and compressibility of the flow, the numerical simulation of oil flow in the pilot stage of the deflector jet pressure valve can be performed through the mass conservation equation, the momentum conservation equation, and the standard $k-\varepsilon$ transport equation. The mass conservation equation and momentum conservation equation are shown as

$$
\begin{gathered}
\nabla \cdot(\rho v)=0 \\
\nabla \cdot(\rho v v)=-\nabla p+\nabla(\tau)+\rho g+F,
\end{gathered}
$$

where $\rho$ is the fluid density. $v$ is the fluid velocity. $p$ is the pressure on fluid microelement. $T$ is the stress tensor. $\rho g$ and $F$ are the gravitational body force and force body force, respectively.
(2) Discrete Phase Model. The volume fraction of solid particles in the hydraulic oil of the servo valve is far less than $10 \%$; thus, the discrete phase model (DPM) in FLUENT can be used to simulate the movement of solid particles.

Particle force equation: analyzing the force of particles, the particle motion equation is established shown in Equation (25), then solve the differential equation in the Lagrangian coordinate system to obtain the motion orbit of particles.

$$
\frac{\mathrm{d} u_{\mathrm{p}}}{\mathrm{dt}}=F_{\mathrm{d}}\left(u_{l}-u_{\mathrm{p}}\right)+\frac{g_{x}\left(\rho_{\mathrm{p}}-\rho\right)}{\rho_{\mathrm{p}}}+F_{\mathrm{x}},
$$

where $u_{\mathrm{p}}$ and $u_{l}$ are the velocity of the particle and liquid. $\rho_{\mathrm{p}}$ and $\rho$ are the density of particle and liquid. $F_{\mathrm{d}}\left(u_{l}-u_{\mathrm{p}}\right)$ is the drag force on particles. $g_{x}\left(\rho_{\mathrm{p}}-\rho\right) / \rho_{\mathrm{p}}$ is the gravity of particles. $F_{x}$ is the additional force

Wall collision model: the particles move with hydraulic oil and will be back to the flow field when bounced against the wall. The rebound coefficient proposed by Grant and Tabakoff is used to describe the change of normal and tangential directions' momentum of particles before and after collision with the wall [19]

$$
\begin{aligned}
& e_{n}=\frac{v_{n 2}}{v_{n 1}}=0.993-1.76 \theta+1.56 \theta^{2}-0.49 \theta^{3} \\
& e_{t}=\frac{v_{t 2}}{v_{t 1}}=0.998-1.66 \theta+2.11 \theta^{2}-0.67 \theta^{3}
\end{aligned}
$$

Particle distribution model: different diameter particles are distributed in the contaminated oil, which can be expressed by Rosin-Rammler [20] shown as

$$
y_{d}=e^{-(d / \bar{d})^{n}}
$$

where $d$ and $\bar{d}$ are the diameter and the mean diameter of particles, respectively; the value of $\bar{d}$ is obtained by noting that value of $d$ at which $y_{d}=e^{-1} \approx 0.368 ; y_{d}$ is the mass 
fraction with diameter greater than $d$; and $n$ is the spread parameter, and the value for $n$ is given as [20]

$$
n=\frac{\ln \left(-\ln y_{d}\right)}{\ln (d / \bar{d})}
$$

Erosion wear model: the model proposed by Edwards et al. [21] through carrying out erosion experiments of sand to the surface of carbon steel, which is used for the erosion rate's calculation of servo valve shown in Equation (29).

$$
R_{e}=\sum_{p=1}^{N} \frac{m_{p} C\left(d_{p}\right) f(\alpha) v^{b(v)}}{A_{f}}
$$

where $R_{\mathrm{e}}$ is the erosion rate. $p$ is the particle number. $m_{p}$ is the mass flow rate of the particle. $D_{p}$ is the diameter of particle. $C\left(d_{p}\right)$ is the function of particle diameter. $\alpha$ is the impact angle between particle trajectory and wall. $f(\alpha)$ is the function of impact angle; the value of $f(\alpha)$ is shown as Table $1 . b$ $(v)$ is the function of particle's relative velocity. $A_{\mathrm{f}}$ is the area of the particle impact wall

(3) Performance Degradation Mechanism Model. Contaminated oil is ejected from the deflector at a high speed and impact angle, and erosion wear will occur on the two receivers and the platform between them, which cause material removal at the top of the boss as shown in Figure 7. During the erosion wear process, the size change of pilot stage includes the increase of longitudinal wear dimension $L_{e}$ and the increase of distance $e$ between the receiver holes, where the relationship between $L_{e}$ and $e$ is shown in Equation (30). Ignoring the effect of $L_{e}$ 's change on the pressure gain of pilot stage, it is necessary to theoretically analyze the effect of $e$ 's change on the pressure gain.

The flow diagram of oil in the pilot stage is shown in Figure 8; the oil enters the V-groove of deflector plate with pressure $p_{i}$ from the top and then ejects from the deflector plate nozzle with $p_{1}$ after accelerating and reducing pressure. The pressure at the left and right receivers is, respectively, $p_{4}\left(Q_{4}\right)$ and $p_{3}\left(Q_{3}\right)$, and some oil flows out of the pilot stage with flow $Q_{5}$ and $Q_{6}$ through the gap. The top view of the dotted line part is shown in Figure 9.

$$
L_{e}=h-(L-e)\left(\frac{\tan (\alpha)}{2}\right) \text {. }
$$

When the deflector plate is in zero position, the load flow is zero, and the inlet pressure of the two receivers is equal:

$$
p_{3}=p_{4}=\frac{1}{1+(K-1)^{2}} p_{1}
$$

where $K=2 c /(B-e)$, which is used to indicate the positional relationship between the deflector nozzle and the inlet of receivers.
TABLE 1: The relationship between $f(\alpha)$ and $\alpha$ [22].

\begin{tabular}{lcc}
\hline Number & Angle $\alpha\left(^{\circ}\right)$ & $f(\alpha)$ valve \\
\hline 1 & 0 & 0 \\
2 & 20 & 0.8 \\
3 & 30 & 1 \\
4 & 45 & 0.5 \\
5 & 90 & 0.4 \\
\hline
\end{tabular}

The pressure gain $k_{p}$ of pilot stage is shown in Equation (32) [23]. The parameter change caused by erosion will not change $p_{1}$, so the analysis of pilot stage pressure gain $k_{p}$ 's change trend is shown in Figure 10, which is combined with Equation (30) to prove erosion wear will cause a decrease in the value of $k_{p}$ and will cause system performance to deteriorate.

$$
k_{p}=\frac{4(K-1)(K-2)}{[(K-1) c+(1-(K / 2))(B-e)]\left[1+(K-1)^{2}\right]} p_{1}
$$

5.1.2. The Erosion Wear Simulation and Analysis of Pilot Stage. The flow field from the deflector to receiver is relatively complicated, and the erosion rate is the largest; thus, the grid is encrypted in these places and numerical simulation of erosion rate is performed using FLUENT. Set $21 \mathrm{MPa}$ pressure as the inlet boundary condition, $0.5 \mathrm{MPa}$ pressure as the outlet boundary condition, $1070 \mathrm{~kg} / \mathrm{m}^{3}$ as the oil density, and 0.0123 Pas as the oil dynamic viscosity. On the basis of continuous phase's convergence, the discrete phase model is set up to simulate the movement of particles and calculate the erosion rate. The concentration and distribution of particles in the oil is determined according to the GJB420B standard shown in Table 2 [24]. The particle distribution obey the Rosin-Rammler distribution, the average diameter of particles is set as $44 \mu \mathrm{m}$, the spread parameter is set as 1.52 , and the Discrete Random Walk model is used to deal with the interaction between the particles and the discrete vortex of the fluid; based on all the above setting, the actual different operating conditions are numerically simulated.

(1) Simulation When Deflector is in Zero Position. When the deflector is in zero position, the flow velocity distribution of the pilot stage is shown in Figure 11. The oil enters the jet disc from the inlet, decreases pressure and increases speed at the constriction neck, and finally collides with the receiver and its middle part and flows to the outlet. The trajectory of the contaminated particles moving along is shown in Figure 12. The place where the most intense collision of particles is the boss in the middle of the receivers can be found, and according to the model of erosion rate on the impact angle and velocity parameters, it can be inferred that the maximum erosion rate is shown in Figure 13; its maximum value is $4.60 e-9\left(\mathrm{~kg} / \mathrm{m}^{2} \mathrm{~s}\right)$.

(2) The Relation between the Erosion Rate and Offset of Deflector. According to the actual situation, several groups of oil velocity and erosion rate are calculated after changing 


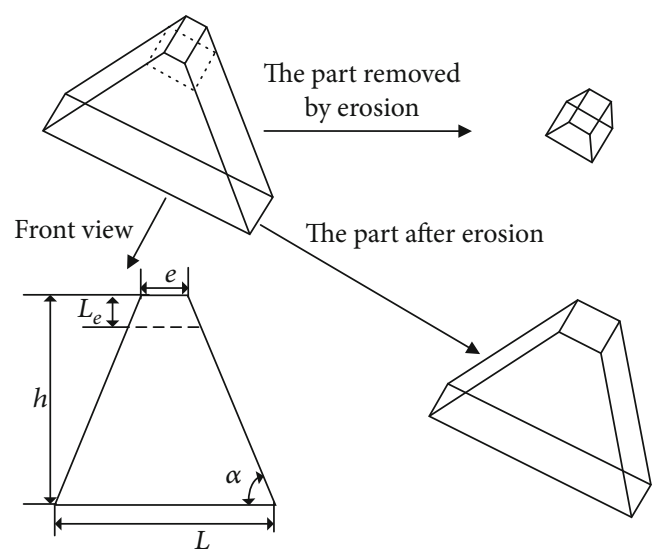

Figure 7: Material removal at the top of the boss.

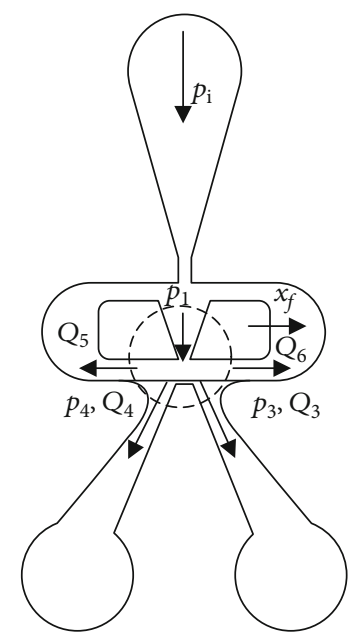

Figure 8: The schematic diagram of the flow distribution in pilot stage.

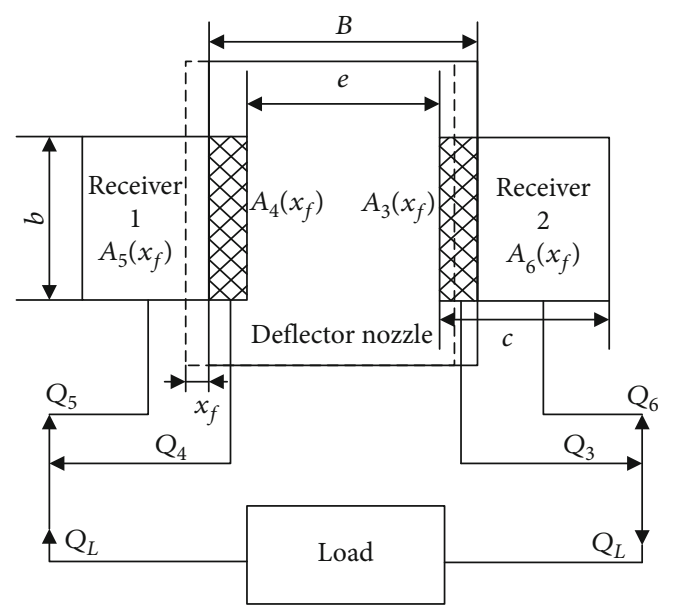

FIgURE 9: The relative position between the nozzle of the deflector and the receiver.

the offset of deflector, of which the relation curves shown in Figure 14 are fitted using MATLAB. It is easy to find that the maximum oil velocity of pilot stage is basically the same

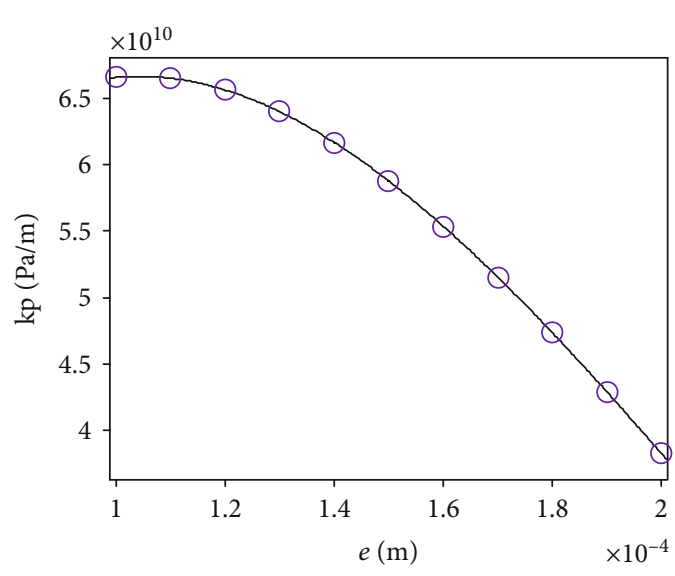

FIgURE 10: The relationship between $k_{p}$ and $e$.

and fluctuates up and down at $188 \mathrm{~m} / \mathrm{s}$, the reason of which is the pressure difference between inlet and outlet and the structures are the same. However, the change of erosion rate shows a certain rule. In the range of $0-0.07 \mathrm{~mm}$, the erosion rate basically fluctuates up and down at $4.5 e-9\left(\mathrm{~kg} \cdot \mathrm{m}^{-2} \cdot \mathrm{s}^{-1}\right)$ and reaches the maximum value at $0.07 \mathrm{~mm}$, and then decreases rapidly with the increase of offset. The reason is the width of middle boss is $0.14 \mathrm{~mm}$; thus, $0.07 \mathrm{~mm}$ is the contact point between the boss and receiving hole, and the difference of flow track of $0-0.07 \mathrm{~mm}$ is small, while the special structure, that $0.07 \mathrm{~mm}$ is the contact point, results in the maximum erosion rate, and after which the erosion rate decreases rapidly with the increase of displacement due to the space between the receive get bigger.

(3) The Relation between the Erosion Rate and Diameter of Particles. The diameter of particles is set as $1 \mu \mathrm{m}, 3 \mu \mathrm{m}$, $5 \mu \mathrm{m}, 7 \mu \mathrm{m}, 8 \mu \mathrm{m}, 10 \mu \mathrm{m}, 15 \mu \mathrm{m}, 20 \mu \mathrm{m}, 25 \mu \mathrm{m}, 50 \mu \mathrm{m}$, $60 \mu \mathrm{m}, 70 \mu \mathrm{m}, 80 \mu \mathrm{m}, 90 \mu \mathrm{m}$, and $100 \mu \mathrm{m}$, respectively, and other parameters are completely consistent. The simulation and fitting results shown in Figure 15 are the relation curves among oil velocity, erosion rate, and particle diameter. It is not difficult to know that the oil velocity follows the same rule, that is, it fluctuates slightly up and down at $188 \mathrm{~m} / \mathrm{s}$. However, the erosion rate increases with the increase of particle diameter on the whole; the reason is under the same condition of other parameters, the increase of particle diameter will lead to the increase of erosion rate because of the larger impact energy of particles. However, there are many fluctuations in the whole particle range, and the particle diameter corresponding to the minimum erosion rate is $7 \mu \mathrm{m}$, while the difference is small in the range of $1-50 \mu \mathrm{m}$.

(4) The Relation between the Erosion Rate and Concentration of Particle. Figure 16 shows the relation curves among the oil velocity, erosion rate, and concentration of particles, in which the particle diameter is fixed at $50 \mu \mathrm{m}$; the concentration of particles is set, respectively, as $0.63 e-14 \mathrm{~kg} / \mathrm{s}, 1.25 e$ $-14 \mathrm{~kg} / \mathrm{s}, 2.5 e-14 \mathrm{~kg} / \mathrm{s}, 5 e-14 \mathrm{~kg} / \mathrm{s}, 1 e-13 \mathrm{~kg} / \mathrm{s}, 2 e-13$ $\mathrm{kg} / \mathrm{s}, 4 e-13 \mathrm{~kg} / \mathrm{s}, 8 e-13 \mathrm{~kg} / \mathrm{s}, 16 e-13 \mathrm{~kg} / \mathrm{s}$, and $32 e-13$ $\mathrm{kg} / \mathrm{s}$, and other parameters are completely consistent. The oil velocity follows the same rule, that is, it fluctuates slightly 
TABle 2: The contamination degree data (particle number per $100 \mathrm{~mL}$ ) of GJB420B.

\begin{tabular}{lcccccc}
\hline Level & $>1 \mu \mathrm{m}$ & $>5 \mu \mathrm{m}$ & $>15 \mu \mathrm{m}$ & $>25 \mu \mathrm{m}$ & $>50 \mu \mathrm{m}$ & $>100 \mu \mathrm{m}$ \\
\hline 1 & 1560 & 609 & 109 & 20 & 4 & 1 \\
2 & 3120 & 1220 & 217 & 39 & 7 & 1 \\
3 & 6250 & 2430 & 432 & 76 & 13 & 2 \\
4 & 12500 & 4860 & 864 & 152 & 26 & 4 \\
5 & 25000 & 9730 & 1730 & 306 & 53 & 8 \\
6 & 50000 & 19500 & 3460 & 612 & 106 & 16 \\
7 & 100000 & 38900 & 6920 & 1220 & 212 & 32 \\
8 & 200000 & 77900 & 13900 & 2450 & 424 & 64 \\
9 & 400000 & 156000 & 27700 & 4900 & 848 & 128 \\
10 & 800000 & 311000 & 55400 & 9800 & 1700 & 256 \\
\hline
\end{tabular}

Contour-25

Velocity magnitude (mixture)
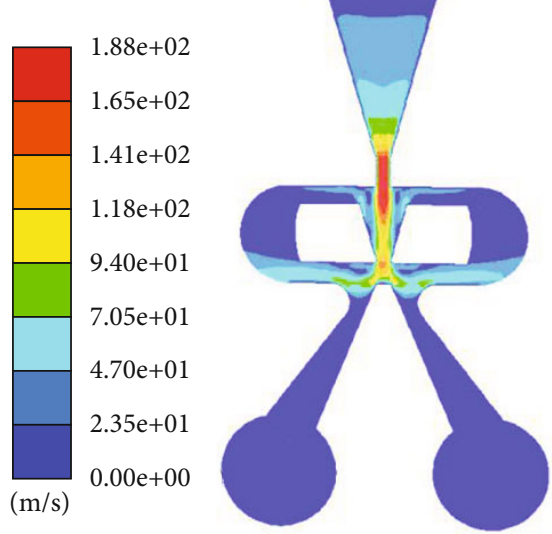

FIgURE 11: The flow velocity distribution of pilot stage.

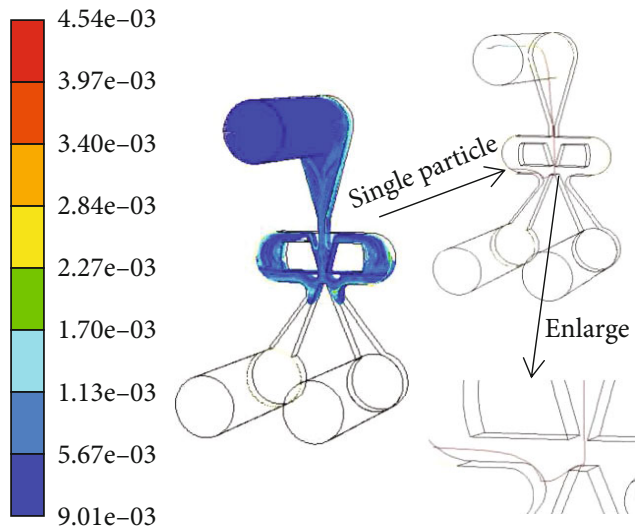

FIGURE 12: The particle trajectory of the pilot stage.

up and down at $188 \mathrm{~m} / \mathrm{s}$. However, the relationship between the increase of erosion rate and the increase of particle concentration is almost linear, because in the effective range of particle concentration, the removal amount of the receiver

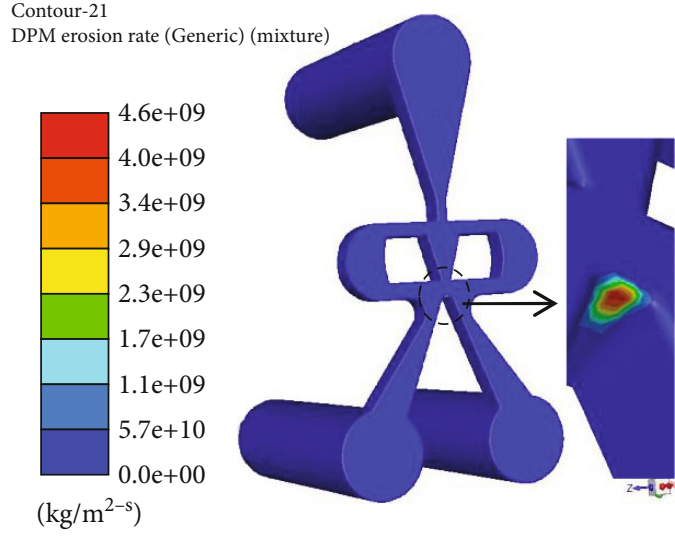

FIgURE 13: The diagram of erosion rate distribution.

as the target is directly proportional to the amount of contamination particles.

(5) The Relation between the Erosion Rate and Oil Pollution Level. According to GJB420B, different oil pollution levels contain the same particle diameter distribution, but the particle concentration is different. The oil pollution levels are set as $1,2,3,4,5,6,7,8,9$, and 10 , respectively, and other parameters are completely consistent. The simulation and fitting results shown in Figure 17 is the relation curves among oil velocity, erosion rate, and oil level. The oil velocity follows the same rule, that is, it fluctuates slightly up and down $188 \mathrm{~m} / \mathrm{s}$. However, the erosion rate increases exponentially with the increase of oil pollution level. The reason for this result is that although the particle diameter distribution of different oil pollution level is completely consistent, but the particle concentration between adjacent oil pollution levels meets the relationship of twice.

5.2. Spool Movement Failure of Slide Valve Stage. The movement of contamination particles in the clearance is mainly the translation with the oil and the rotation around its center of gravity. Because most of them are ellipsoidal, when the size of particles along the radial direction of slide valve is smaller than the clearance, they can enter the clearance with oil. In the rotation movement, the size of ellipsoidal particles along the radial direction of the clearance will change due to the different rotation angles. When the radial size of particles increases to the same size as the radial size of clearance, the particles are trapped in the clearance of the slide valve.

\subsubsection{Mathematical Model of the Degradation Process}

(1) Interaction Model between Contamination Particles and Motion Pair Surfaces. As shown in Figure 18, when the contamination particles contact with the valve core and valve sleeve, the normal deformation $\delta_{1}$ and $\delta_{2}$ are generated in the upper and lower hemispheres under the action of clamping force $F_{N 1}$ and $F_{N 2}$ due to different surface hardness of the valve core and valve sleeve, which make the shape of particles from a dotted line profile to a solid line profile. When the 


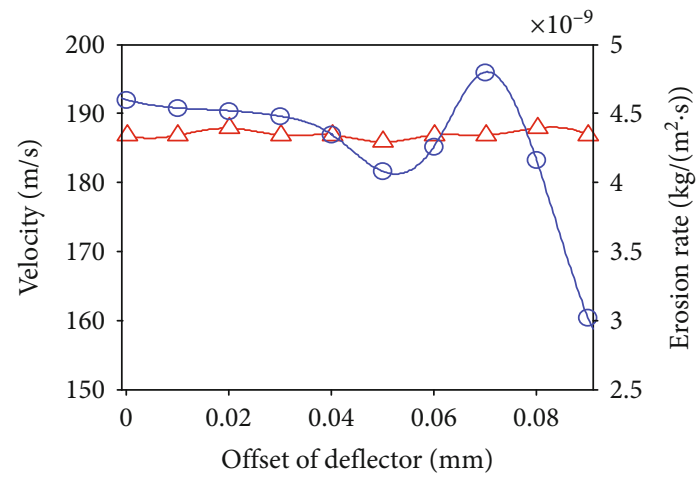

FIgURE 14: The relation curves among oil velocity, erosion rate, and deflector's offset.

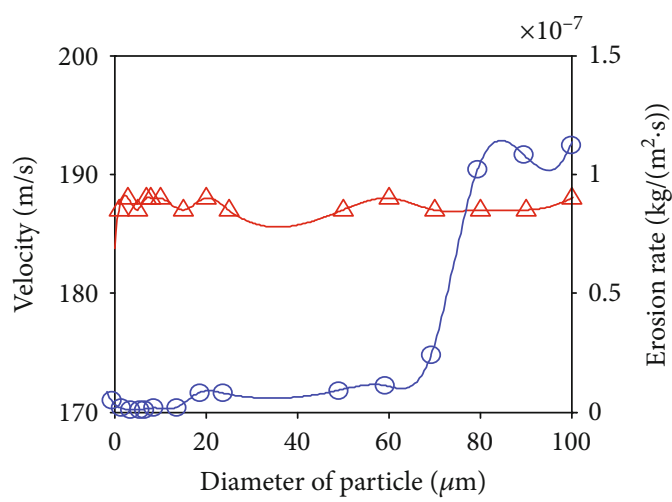

FIGURE 15: The relation curves among oil velocity, erosion rate, and particle's diameter.

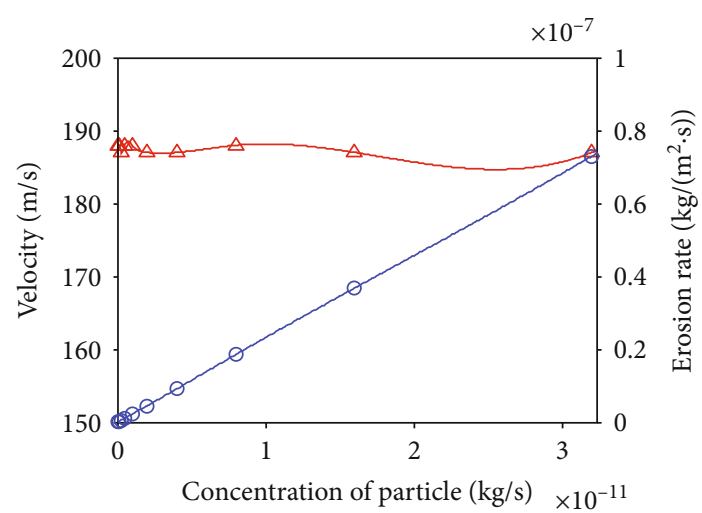

FIGURE 16: The relation curves among oil velocity, erosion rate, and particle's concentration.

bearing stress reaches the stress limit, the contamination particles are crushed [25].

The hardness of valve core and valve sleeve is $H B_{1}$ and $H B_{2}$, respectively; the stress limit of particles is $\sigma$; and the

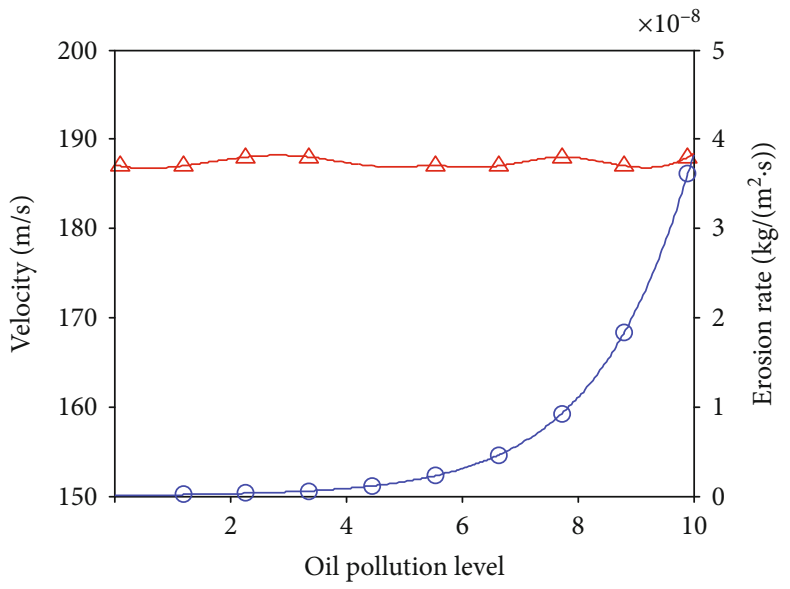

FIGURE 17: The relation curves among oil velocity, erosion rate, and oil pollution level.

equivalent diameter of particles is $d_{d x}$. It can be seen from the analysis of elasticity that

$$
\begin{aligned}
F_{i} & =\frac{4}{3} E_{i}^{\prime}\left(\frac{d_{d x}}{2}\right)^{0.5} \delta_{i \max }^{1.5}, \\
F_{N i} & =H B_{i} \cdot \pi a_{i}^{2}, \\
a_{i} & =\left(\frac{3 F_{i} d_{d x}}{8 E_{i}^{\prime}}\right)^{1 / 3}, \\
F_{\sigma} & =\frac{1}{4} \sigma \pi d_{d x}^{2} .
\end{aligned}
$$

There are

$$
\begin{aligned}
E_{i}^{\prime} & =\frac{3 H B_{i}^{3 / 2} \pi}{4 \sigma^{1 / 2}}, \\
\delta_{i \max } & =\frac{\sigma d_{d x}}{2 H B_{i}} .
\end{aligned}
$$

The research shows that the eccentricity of valve core and valve sleeve is generally between $15 \%$ and $20 \%$. For the contamination particles with diameter $d$ ( $d$ refers to the maximum diameter of particles, and the ratio of maximum diameter to minimum diameter is defined as $K$ ), the interaction types on the surface of slide valve pair with eccentricity $e_{1}$ varies with its position in the clearance, which is shown in Figure 19.

For particles with diameter $d$ in the sensitive dimension $\left(h-e_{1}, K\left(h+e_{1}\right)\right)$, the radial clearance is divided into three areas according to the different interaction between the particle and surface of slide valve pair.

(1) No action area. In the area with circumferential angle of $\left(0, \theta_{1}\right)$, the minimum diameter of particles is larger than the clearance, and the contamination particles cannot enter the clearance; in the area with a circumferential angle of $\left(\theta_{3}, \pi\right)$, the maximum diameter of 


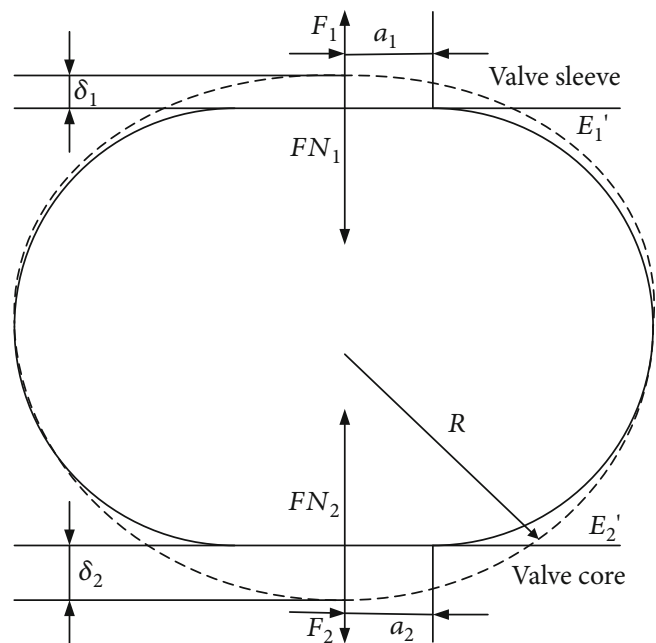

FIgURE 18: Interaction model between contamination particles and motion pair surfaces.

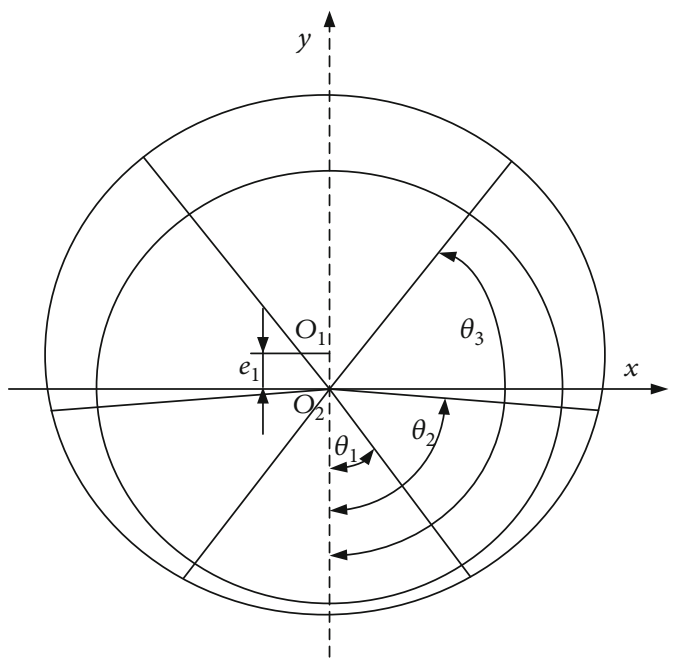

Figure 19: Interaction area between contamination particles and side valve surface.

particles is smaller than the clearance and there are no interaction between the contamination particles and slide valve pairs in the above areas. The $\theta_{1}$ and $\theta_{3}$ are calculated as follows [25]:

$$
\begin{gathered}
\theta_{1}=\arccos \left(\frac{h-d / K}{e_{1}}\right), \\
\theta_{3}=\arccos \left(\frac{h-d}{e_{1}}\right)
\end{gathered}
$$

(2) Crushing area. In the area with a circumferential angle of $\left(\theta_{1}, \theta_{2}\right)$, the particles with diameter $d$ enter the clearance. When the slide valve starts, the equiv- alent diameter $d_{d x}$ of particles is equal to its maximum diameter $d$, and the deformation reaches the maximum value. The calculation of $\theta_{2}$ is as follows:

$$
\theta_{2}=\arccos \left(\frac{1}{e_{1}}\left(h-d+\frac{\sigma d\left(H B_{1}+H B_{2}\right)}{2 H B_{1} \cdot H B_{2}}\right)\right)
$$

(3) Deformation zone. In the area with a circumferential angle of $\left(\theta_{2}, \theta_{3}\right)$, the particles with diameter $d$ can enter and be trapped in the clearance due to rotation. When the valve core is started, the particles will be squeezed and deformed, and there will be a certain clamping force among the valve core, valve sleeve, and contamination particles

\section{(2) Clamping Force Model of Single Particle.}

(1) Calculation of clamping force in crushing area. In the area of circumferential angle $\left(\theta_{1}, \theta_{2}\right)$, the particles with diameter $d$ reaches the stress limit and the deformation reaches the maximum value when the valve core is started. At this time, the equivalent diameter of the particle has not reached its diameter $d$, the equivalent diameter is related to the position of the particle, namely,

$$
\begin{gathered}
d_{d x}=h_{\theta}+\delta_{1 \max }+\delta_{2 \max }, \\
d_{d x}=\frac{h_{\theta}}{1-\left(\sigma / 2 H B_{1}\right)-\left(\sigma / 2 H B_{2}\right)} .
\end{gathered}
$$

When the circumferential angle is $\theta_{2}, d_{d x}=d$.

In the strength limit region, the deformation of particles reaches the maximum value $\delta_{1 \max }$ and $\delta_{2 \max }$, so the clamping force of particles is

$$
F_{1}=\frac{1}{4} \sigma \pi d_{d x}^{2}=\frac{\sigma \pi\left(h-e_{1} \cos (\theta)\right)^{2}}{\left(2-\left(\sigma / 2 H B_{1}\right)-\left(\sigma / 2 H B_{2}\right)\right)^{2}}
$$

(2) Calculation of clamping force in deformation area. In the area of circumferential angle $\left(\theta_{2}, \theta_{3}\right)$, when the valve core is started, the particles are squeezed by the valve core and valve sleeve, and the equivalent diameter of the contamination particles is the maximum diameter $d$, namely,

$$
\begin{gathered}
d=h_{\theta}+\delta_{1}+\delta_{2} \\
F_{2}=\frac{\pi d^{1 / 2}\left(d+e_{1} \cos (\theta)-h\right)\left(H B_{1} \cdot H B_{2}\right)^{3 / 2}}{(2 \sigma)^{1 / 2}\left(H B_{1}^{3 / 2}+H B_{2}^{3 / 2}\right)}
\end{gathered}
$$

(3) Interception Probability model. 
(1) Theoretical interception probability. The interception probability $P_{d}(\theta)$ of ellipsoid particles with diameter $d$ and ratio $K$ of long axis to short axis can be intercepted at the circular angle $\theta$ is

$$
P_{d}(\theta)=\frac{h_{\theta}-(d / K)}{d-(d / K)}, \quad \theta_{1} \leq \theta \leq \theta_{3}
$$

(2) Actual interception probability. The actual interception probability $P(\theta)$ is

$$
P(\theta)=P_{d}(\theta) \cdot \varepsilon, \quad \theta_{1} \leq \theta \leq \theta_{3}
$$

where the determination of $\varepsilon$ is related to the probability of the system oil entering into the clearance and the probability of particles sticking in the clearance:

$$
\varepsilon=\frac{\pi d h^{3}}{24 \mu L Q_{t}} \Delta p\left(1+1.5 \xi^{2}\right)
$$

\section{(4) Performance Degradation Mechanism Model.}

(1) Clamping force of single particles in the clearance of slide valve

Because the clamping force of the particles with diameter $d$ in the crushing area and deformation area changes with the change of circumference angle $\theta$, and the actual interception probability $P(\theta)$ is also related to the circular angle $\theta$, there is

$$
F_{d}=\int_{\theta_{1}}^{\theta_{2}} F_{1} p(\theta) \mathrm{d} \theta+\int_{\theta_{2}}^{\theta_{3}} F_{2} p(\theta) \mathrm{d} \theta
$$

where $F_{1}$ and $F_{2}$ are, respectively, the clamping forces of particles in the crushing area and the deformation area

(2) The clamping force of contamination particles in the clearance of slide valve

The research results show the size distribution of contamination particles in the hydraulic system is close to the modified lognormal distribution, which can be expressed as follows:

$$
F(d)=1-e^{-B \ln ^{2} d}
$$

where $B$ is the distribution parameter

Since the slide valve pair's initial clearance of deflector jet pressure servo valve is $2 \mu \mathrm{m}-4 \mu \mathrm{m}$, the particle data below $5 \mu \mathrm{m}$ is not involved in NAS1638, so the determination of contamination particle's mass fraction distribution basing on GJB420B is shown in Figure 20.

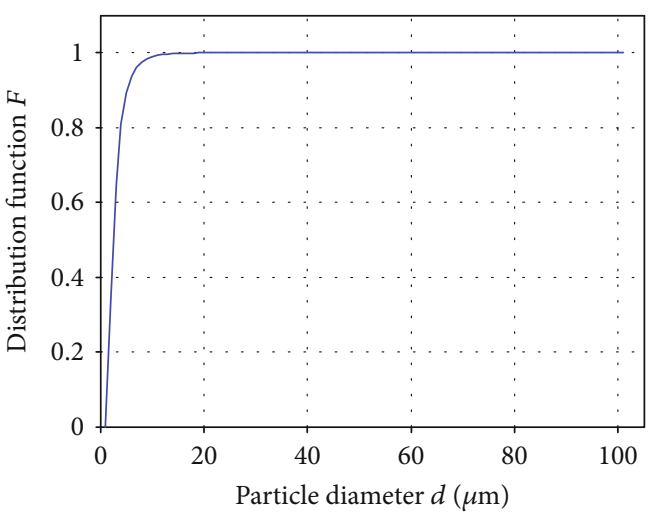

Figure 20: The contamination particle's mass fraction distribution of GJB420B.

When the static time of valve core is $t$, the leakage of the slide valve is

$$
Q_{t}=\int_{0}^{t} q_{0} e^{-t / \tau} d t=\tau q_{0}\left(1-e^{-t / \tau}\right)
$$

where $\tau$ is the time constant of filter cake from stable stage to saturation stage. When the structure of valve core and valve sleeve is determined, the value of time constant is mainly related to oil pollution level and particle distribution, and its calculation is shown in

$$
\tau=\frac{6 \times 10^{3} K^{2}\left(D^{2}-d_{x}^{2}\right)\left(1-\varepsilon_{c}\right)}{4 N_{i}\left(q_{0}-(p A / \alpha \mu L \rho)\right) \sum_{1}^{K\left(h+e_{1}\right)} d^{3}(F(d+\Delta d)-F(d))},
$$

where $\varepsilon_{c}$ is the ratio of hollow diameter of filter cake to clearance. $N_{i}$ is the total number of contamination particles in oil pollution level of $i . \alpha$ is the specific resistance of filter cake. $\Delta d$ is the increment of particle diameter when counting the particle number.

The clamping force produced by contamination particles in the clearance is as follows:

$$
F=\sum_{h-e_{1}}^{K\left(h+e_{1}\right)} 2 F_{d} N_{n} Q_{t}[F(d+\Delta d)-F(d)]
$$

The axial clamping friction force $F_{f}$ to be overcome in the movement of valve core is

$$
F_{f}=k F,
$$

where $k$ is the clamping coefficient.

\subsubsection{Calculation and Analysis of Clamping Force of Valve Core}

(1) The Relation between the Friction Force and Particle Diameter. In order to obtain the relation between clamping force of particle diameter, the contamination oil is designed to meet the pollution level of GJB420B 7, and the diameter 


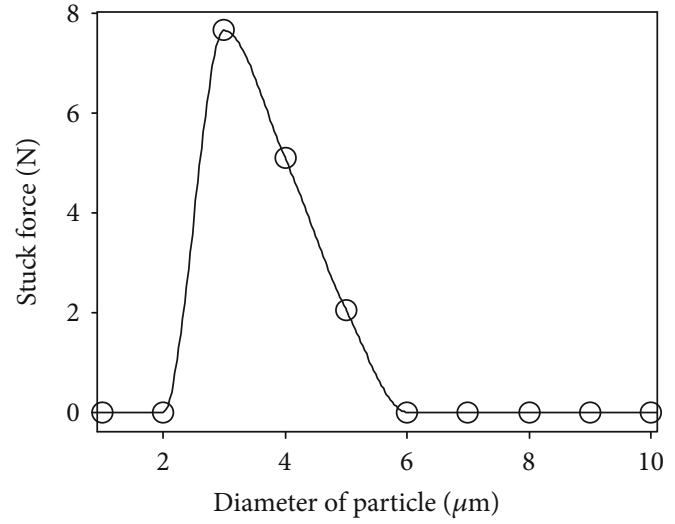

FIgURE 21: The relation curve between clamping friction force and the particles diameter.

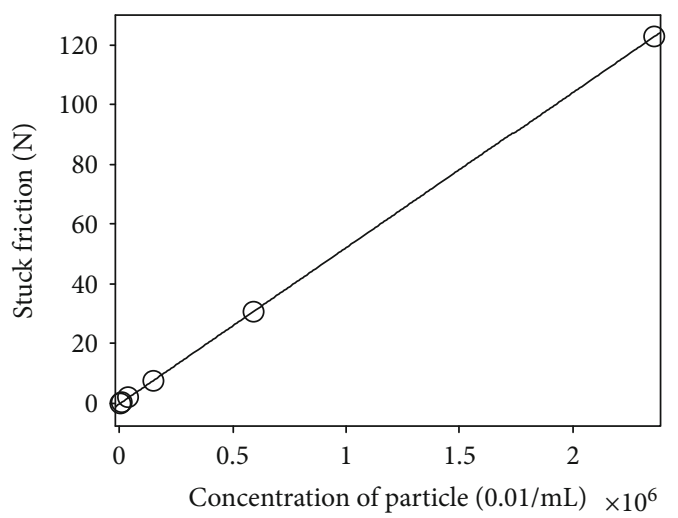

FIGURE 22: The relation curve between sticking friction force and the particle concentration.

of contamination particles is selected as $1 \mu \mathrm{m}, 2 \mu \mathrm{m}, 3 \mu \mathrm{m}$, $4 \mu \mathrm{m}, 5 \mu \mathrm{m}, 6 \mu \mathrm{m}, 7 \mu \mathrm{m}, 8 \mu \mathrm{m}, 9 \mu \mathrm{m}$, and $10 \mu \mathrm{m}$, respectively. The clamping friction force is $7.66 \mathrm{~N}$ under $3 \mu \mathrm{m}$ contamination particles. Similarly, the friction force under $5 \mu \mathrm{m}$ particles is $2.05 \mathrm{~N}$, while $1 \mu \mathrm{m}, 2 \mu \mathrm{m}, 6 \mu \mathrm{m}, 7 \mu \mathrm{m}, 8 \mu \mathrm{m}, 9 \mu \mathrm{m}$, and $10 \mu \mathrm{m}$ are not within the range of effective particle diameter, so the friction force calculated are $0 \mathrm{~N}$. Thus, the relation between clamping force of the valve core and the particles diameter is shown in Figure 21.

(2) The Relation between the Friction Force and Particle Concentration. Set the particle diameter as $3 \mu \mathrm{m}$ and take the particle concentration (particle number) as $2307 / 100 \mathrm{~mL}$, 9225/100 mL, 36905/100 mL, 147596/100 mL, 590824/100 mL, and $2362494 / 100 \mathrm{~mL}$, respectively. After calculation, the curve between the clamping force of valve core and the particle concentration is obtained as Figure 22. It is not difficult to find the clamping force under $3 \mu \mathrm{m}$ particles increases with the increase of the particle concentration, and the relationship between them is almost linear.

(3) The Relation between the Friction Force and Oil Pollution Level. In order to research the effect of oil pollution on the clamping force as real as possible, the particle diameter range

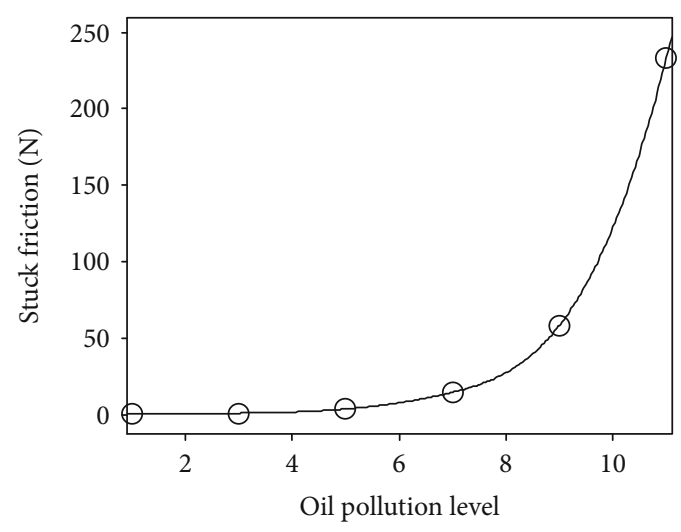

FIGURE 23: The relation curve between the friction force and oil pollution level.

was extended from $3 \mu \mathrm{m}$ to the full scale range, and the oil pollution level is selected as level 1 , level 3, level 5, level 7, level 9, and level 11 based on the GJB420B. According to the analysis and calculation results, the curve between the clamping friction force of valve core and the oil pollution level is shown in Figure 23. It can be found that the increase of oil pollution level will cause the clamping friction force of the valve core to increase exponentially.

5.3. The Service Life Prediction of Deflector Jet Pressure Servo Valve. Under the condition of oil pollution, the service life of the deflector jet pressure servo valve is closely related to the erosion of the pilot stage and the clamping of the valve core. The erosion rate of pilot stage and the clamping force of valve core increase with the increase of oil pollution level. Through the analysis and calculation, the erosion rate and the clamping force of the valve core can be obtained under different pollution levels, and then, the service life of the pressure valve can be obtained by combining the failure critical value of the key deterioration parameter.

5.3.1. The Determination of Failure Critical Value. According to the regulation time, overshoot and steady state error of pressure valve's dynamic response, the failure critical value of its life, is determined. There are many kinds of actual systems and there is no unified system index requirement. In this paper, $\alpha_{s}$ is set as the multiple of required initial regulation time $t_{s}$, that is, with the decline of system performance, when the regulation time exceeds $\alpha_{s} t_{s}$, the system is considered failure. $\beta_{\sigma}$ is the required overshoot index, $\gamma_{E}$ is the ratio of the required steady state error $E_{\Delta}$ to the desired output of the system, and the failure critical value of the system is determined according to Equation (49). Select $\alpha_{s}=2, \beta_{\sigma}=$ $25 \%$, and $\gamma_{E}=20 \%$ to determine the critical value of the parameters when the valve system fails.

$p_{\mathrm{a}}=\left\{\begin{array}{l}\max \left(p_{\alpha_{s}}, p_{\beta_{\sigma}}, p_{\gamma_{E}}\right), p_{a} \text { decrease during the failure, } \\ \min \left(p_{\alpha_{s}}, p_{\beta_{\sigma}}, p_{\gamma_{E}}\right), p_{a} \text { increase during the failure, }\end{array}\right.$ 


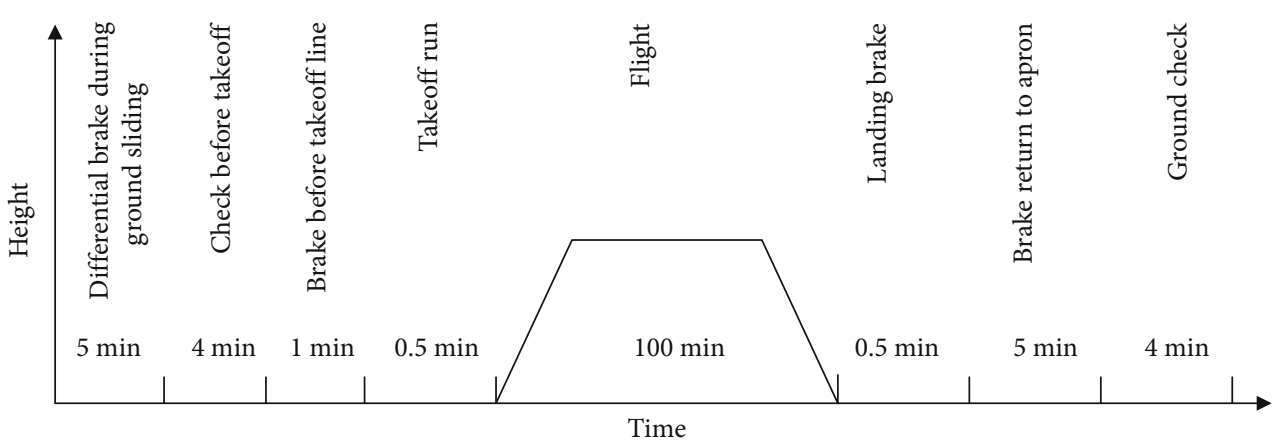

FIGURE 24: Mission profile of the aircraft brake system.

TABLE 3: The service life under erosion and sticking.

\begin{tabular}{lccc}
\hline Oil pollution level & 6 & 7 & 8 \\
\hline Sticking force(N) & 7.29 & 14.57 & 29.17 \\
Critical pressure gain of pilot stage $(\mathrm{pa} / \mathrm{m})$ & $4.45 \times 10^{10}$ & $4.71 \times 10^{10}$ & $5.25 \times 10^{10}$ \\
Erosion length (mm) & 0.0624 & 0.0515 & 0.0395 \\
Life under single oil level (flight takeoff landing) & 24191 & 9982 & 3814 \\
Service life (flight takeoff landing) & & 8812 \\
\hline
\end{tabular}

where $p_{a}$ is the critical value of valve failure parameter. $p_{\alpha s}$ is the critical value determined by regulating time of valve failure parameter. $p_{\beta \sigma}$ is the critical value determined by overshoot of valve failure parameter. $p_{\gamma E}$ is the critical value determined by steady state error of valve failure parameter.

5.3.2. The Service Life Prediction Model. Shown in Figure 24 is the mission profile of an aircraft's braking system. In one flight cycle, the servo valve receives the electric control signal from the flight control system except the flight phase, in which the servo valve do not work. Therefore, in one flight cycle, the time of pilot stage's erosion wear is $20 \mathrm{~min}$; then, the service life of pilot stage's erosion is carried out according to Equations (50)-(59).

$$
\begin{gathered}
N_{e}=\sum_{i=1}^{12} \frac{L_{i} / T_{0}}{E_{i} / \rho}, \\
L_{\max }=\sum_{i=1}^{12} n_{i} L_{i}, \\
\text { If } \sum_{i=1}^{12} \frac{L_{i} / T_{0}}{M E_{i} / \rho}<N_{i} \text {, then } L i+1=0,
\end{gathered}
$$

where $N_{e}$ is the erosion service life in flight takeoff landing. $L_{i}$ is the erosion distance generated under the oil level of $i . E_{i}$ is the erosion rate under the oil level of $i$. $T_{0}$ is the erosion time of single flight takeoff landing. $\rho$ is the density of receivers; $n_{i}$ is the maintenance times of oil level from $i$ to $i+1$. It can be determined according to the actual maintenance; $M$ is the number of flight takeoff landing experienced in single maintenance.
In one flight cycle, the corresponding maximum friction force will be generated in each static phase of valve core such as the takeoff phase, and the friction force will be accumulated from small to large after the switch action of valve core. Therefore, the service life under the influence of friction force can be calculated according to the longest time phase, which is shown in Equations (53) and (54).

$$
\begin{aligned}
N_{f} & =\sum_{i=1}^{12} n_{i} M \delta_{i} \\
\delta_{i} & =\left\{\begin{array}{l}
1,\left(F_{i} \leq F_{\max }\right) \\
0,\left(F_{i}>F_{\max }\right)
\end{array}\right.
\end{aligned}
$$

where $N_{f}$ is the service life of clamping failure in flight takeoff landing. $\delta_{i}$ and $F_{i}$ are the life factor and friction force corresponding to the oil level of $i . F_{\max }$ is the critical friction force of clamping failure.

5.3.3. The Service Life Prediction of Deflector Jet Pressure Servo Valve under the Action of Two Failure Modes. In practice, the service life prediction is relatively complex when the erosion of pilot stage and the stuck of slide valve stage are induced by oil pollution together. It is necessary to comprehensively consider the two failure modes and the changes of key deterioration parameters under different oil pollution levels. Firstly, the clamping friction force under different oil levels are calculated, which is input into the system simulation software and the critical value of pressure gain and erosion distance under different oil levels based on the critical value judgment rule are calculated, then basing on Equation (50)-(54), the life under different oil pollution levels are 
determined and finally the service life of whole valve is determined as shown in Table 3 .

\section{Conclusion}

Aiming at the deflector jet pressure servo valve, a method for performance degradation analysis and service life prediction under the influence of oil pollution is presented.

(1) The sensitivity equation of the output pressure about the key deterioration parameters of the pilot stage's erosion and the slide valve stage's clamping is established and the sensitivity analysis is carried out. It is found that the pilot stage's pressure gain and the slide valve stage's friction force will have a significant impact on the output pressure during the whole response process

(2) Based on the theory of fluid mechanics and erosion, considering the influence of oil pollution level, the numerical simulation of pilot stage's erosion is carried out. The erosion rate increases exponentially with the increase of oil pollution level; when the offset of deflector plate is $0.07 \mathrm{~mm}$, the erosion rate is the largest

(3) Based on the theory of elasticity and filter cake, considering the influence of oil pollution, the friction force's theoretical calculation of slide valve pair's special matching clearance is carried out. The friction force increases exponentially with the increase of oil pollution level, and the friction force caused by the contamination particles with the average clearance diameter of $3 \mu \mathrm{m}$ is the largest

\section{Data Availability}

The data used to support the findings of this study have not been made available because further research.

\section{Conflicts of Interest}

The authors declared no potential conflicts of interest with respect to the research, authorship, and/or publication of this article.

\section{Acknowledgments}

The authors disclosed receipt of the following financial support for the research, authorship, and/or publication of this article. This work was supported by the National Natural Science Foundation of China (NSFC 51805403), the project supported by Natural Science Basic Research Plan in Shaanxi Province of China (NSBRP 2019JQ-836), the Natural Science Foundation of Shaanxi Provincial Department of Education (NSSXE 19JK0416), and the project supported by Xi'an postdoctoral Foundation (2020-621).

\section{References}

[1] Q. Long, J. Ruan, S. Li, and J. F. He, "Stability of 2D pressure servo valve considering cavitation effect," Acta Aeronautica et Astronautica Sinica, vol. 41, no. 5, pp. 291-304, 2020.

[2] Y.Z. Chen, "The initial design concept and applications for the eectrohydraulic servo valve," Machine Tool \& Hydraulics, vol. 47, no. 9, pp. 114-118, 2019.

[3] X. N. Kang, X. G. He, J. T. Wang, J. H. He, and J. F. Ma, "Design and mechanism analysis on a new type of deflector jet pressure servo valve," in The 18th Conference of China Science Association, pp. 26-36, China, September 2016.

[4] Y. B. Yin, Theory and Application of Advanced Hydraulic Component, Shanghai Science and Technology Press, 2017.

[5] S. Kang, H. Yan, and C. C. Li, "Research review of the deflector jet servo valve," Journal of Beijing Jiaotong University, vol. 41, no. 1, pp. 130-139, 2017.

[6] S. H. Somashekhar and M. Singaperumal, "Mathmatical modelling and simulation of a jet pipe electrohydraulic flow servo valve," Journal of Systems and Control Engineering, vol. 221, no. 3, pp. 365-382, 2007.

[7] Y. Liu, Y. Yang, Y. Luo et al., "Prognostic potential of PRPF3 in hepatocellular carcinoma," Aging, vol. 12, no. 1, pp. 912-930, 2020.

[8] Y. B. Yin, P. Zhang, and Y. Zhang, "Analysis of the pressure characteristics of deflector jet servo valve," Fluid Power Transmission and Control, vol. 65, no. 4, pp. 10-15, 2014.

[9] L. Q. Jiang, Design and research on a new type of deflection plate jet pipe servo valve, [M.S. thesis], Southwest University, Nanjing, China, 2013.

[10] Y. X. Shang, X. S. Zhang, and C. W. Hu, "Optimal design for amplifier of a jet deflector servo valve," Hydromechatronics Engingeering, vol. 43, no. 3, pp. 11-15, 2015.

[11] J. Li, Research on measuring method of basic dimensions and geometrical tolerance of jet-pan based on CCD [M.S. thesis], Harbin Institute of Technology, Harbin, China, 2010.

[12] Y. B. Yin, J. H. Fu, and Y. L. Jin, "Numerical simulation of erosion wear of prestage of a jet pipe servo valve," Journal of Zhejiang University, vol. 49, no. 12, pp. 2250-2260, 2015.

[13] Y. B. Chu, Z. H. Yuan, and Y. Zhang, "Erosion wear characteristic of jet pipe servo valve," Acta Aeronautica et Astronautica Sinica, vol. 36, no. 5, pp. 1548-1555, 2015.

[14] Y. Chu, Z. Yuan, and W. Chang, "Research on the dynamic erosion wear characteristics of a nozzle flapper pressure servo valve used in aircraft brake system," Mathematical Problems in Engineering, vol. 2020, Article ID 3136412, 13 pages, 2020.

[15] Y. Chu, Z. Yuan, and J. Chen, "Research on dynamic reliability of a jet pipe servo valve based on generalized stochastic petri nets," International Journal of Aerospace Engineering, vol. 2015, Article ID 171642, 8 pages, 2015.

[16] H. Ji, S. W. Zhang, and X. Q. Liu, "Effect of solid particles on erosion wear of prestage of jet deflector servo valve," Journal of Lanzhou University of Technology, vol. 44, no. 6, pp. 4448, 2018.

[17] Z. Huang, B. G. Hou, and Q. Fang, "Comparison of electro hydr aulic servo valves between jet pipe type and nozzle flapper type," Fluid Power Transmission and Control, vol. 23, no. 4, pp. 43-45, 2007.

[18] G. D. Qi, "Oil pollution and control for elect-hydraulic servo valve in an aeroplane brake system," Machine Tool \& Hydraulics, vol. 40, no. 8, pp. 103-105, 2012. 
[19] G. Grant and W. Tabakoff, "Erosion prediction in turbomachinery resulting from environmental solid particles," Journal of Aircraft, vol. 12, no. 5, pp. 471-478, 1975.

[20] S. W. Zhang, The simulation of erosion on servo valve orifice and changes of valve characteristics on jet deflector servo valve [M.S. thesis], Lanzhou University of Technology, Lanzhou, China, 2017.

[21] J. K. Edwards, B. S. Mclaury, and S. A. Shirazi, "Evaluation of alternative pipe bend fittings in erosion service," in Proceedings of ASME FEDSM'00: ASME 2000 Fluids Engineering Division Summer Meeting, pp. 959-966, Boston, MA, USA, 2000.

[22] K. Zhang, J. Y. Yao, and T. M. Jiang, “Degradation assessment and life prediction of electro-hydraulic servo valve under erosion wear," Engineering Failure Analysis, vol. 36, no. 1, pp. 284-300, 2014.

[23] S. Kang, H. Yan, C. C. Li, F. J. Wang, and S. M. Wang, "Modeling of the flow distribution and characteristics analysis of the pilot stage in a deflector jet servo valve," Journal of Harbin Engineering University, vol. 38, no. 8, pp. 1239-1302, 2017.

[24] GJB420B, Solid Particle Contamination Classes for Fluid of Aviation, Military Standard Publishing Department of General Equipment Department, Beijing, China, 2015.

[25] Z. Q. Liu, Study on stagnation characteristics of power shift steering transmission hydraulic valve in polluted oil [M.S. thesis], Beijing Institute of Technology, Beijing, China, 2016. 